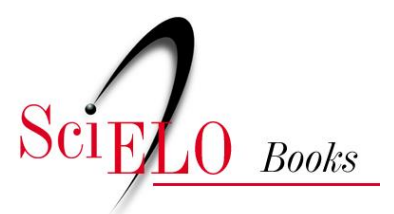

\title{
VII - Antes da lei de 1871
}

\author{
Joaquim Nabuco
}

\section{SciELO Books / SciELO Livros / SciELO Libros}

NABUCO, J. Antes da lei de 1871. In: O abolicionismo [online]. Rio de Janeiro: Centro Edelstein de Pesquisas Sociais, 2011. Antes da lei de 1871. pp. 39-46. ISBN: 978-85-7982-070-0.

https://doi.org/10.7476/9788579820700.0008.

\section{() povour}

This work is free of known copyright restrictions. http://creativecommons.org/publicdomain/mark/1.0/

Este trabalho está livre de restrições de direito de autor e/ou de direitos conexos conhecidas.

http://creativecommons.org/publicdomain/mark/1.0/

Esta obra está libre de restricciones conocidas de derechos autorales. http://creativecommons.org/publicdomain/mark/1.0/ 


\section{VII - ANTES DA LEI DE 1871}

Por cinco anos choveu sobre as almas dos míseros cativos, como o maná sobre os israelitas no deserto, a esperança da liberdade bafejada do trono.

Cristiano Ottoni

As promessas de liberdade do segundo e extenso período desde a Independência do Brasil até a lei Rio Branco datam de poucos anos, relativamente a certa parte da população escrava, e no fim do Primeiro Reinado, relativamente à outra.

Os direitos desta última - que vem a ser os africanos importados depois de 1831 e os seus descendentes - são discutidos mais longe. Por ora basta-nos dizer que esses direitos não se fundam sobre promessas mais ou menos contestáveis, mas sobre um tratado internacional e em lei positiva e expressa. O simples fato de achar-se pelo menos metade da população escrava do Brasil escravizada com postergação manifesta da lei e desprezo das penas que ela fulminou, dispensar-nos-ia de levar por diante este argumento sobre os compromissos públicos tomados para com os escravos.

Quando a própria lei, como se verá exposto com toda a minudência, não basta para garantir, à metade, pelo menos, dos indivíduos escravizados, a liberdade que decretou para eles; quando um artigo tão claro como este: "Todos os escravos que entraram no território ou portos do Brasil, vindos de fora, ficam livres" " nunca foi executado, e a referenda de Diogo Antônio Feijó nunca foi honrada nem pelos ministros da Regência nem pelos do Segundo Reinado: que valor obrigatório podem ter movimentos nacionais de caráter diverso, atos na aparência alheios à sorte dos escravos, declarações oficiais limitadas ao efeito que deviam produzir? Em outras palavras, de que servem tais apelos à consciência, à lealdade, ao sentimento de justiça da nação, quando metade dos escravos estão ilegalmente em cativeiro? Para que apresentar ao Estado a pagamento uma dívida de honra, da qual ele nunca teve consciência ou de todo se esqueceu, quando ele próprio ousadamente

\footnotetext{
${ }^{1}$ Art. $1^{\circ}$ da lei de 7 de novembro de 1831 .
} 
repudiou, alegando coação do estrangeiro, essa escritura pública solene lavrada pela assembleia geral, e rubricada pela Regência Trina?

Útil ou inútil, o protesto dos escravos deve entretanto ser feito em cada uma das suas partes conforme a natureza das obrigações contraídas para com eles. Numa proporção enorme essa obrigação do Estado é para eles uma lei, e uma lei feita em desempenho de um tratado internacional. Por isso mais tarde veremos de que modo e em que termos esse direito dos escravos foi reivindicado perante o governo brasileiro pela diplomacia inglesa. Há infinitamente mais humilhação para nós nesse evidente denegação de justiça por parte daquele, do que no apresamento de navios negreiros em nossos portos por ordem desta. $\mathrm{O}$ nosso argumento, feita essa ressalva importante - que é toda a questão, por assim dizer - refere-se por enquanto aos escravos que nem por si nem por suas mães têm direito à liberdade fundados numa lei expressa. É escusado dizer-se que estes são todos - exceto raros africanos ainda em cativeiro importados no Primeiro Reinado - brasileiros de nascimento.

Os fatos em que estes podem haver fundado uma esperança, e que certamente obrigam a honra do país, datam de pouco antes da lei de 28 de setembro. Esses compromissos nacionais com relação aos escravos existentes são principalmente os seguintes: a alforria de escravos para a guerra do Paraguai; a Fala do Trono de 1867, e a correspondência entre os abolicionistas europeus e o governo imperial; a ação pessoal do conde D'Eu no Paraguai como general em chefe do Exército; a conexão da emancipação anunciada com o fim da guerra; a elaboração do projeto de emancipação no Conselho de Estado; a agitação do Partido Liberal consecutivamente à organização do ministério Itaboraí, a queda desse ministério e a subida do gabinete São Vicente; a oposição à proposta Rio Branco; os vaticínios da dissidência; a guerra organizada contra o governo e o imperador pela lavoura do Sul; a própria lei de 28 de setembro de 1871, interpretada pelos que a defenderam e a sustentaram, e as perspectivas de futuro abertas durante a discussão.

Sem entrar nos detalhes de cada um desses pontos históricos, é possível apontar de modo que não admita nenhuma dúvida de boa fé a relação entre todos eles e a sorte dos escravos.

O efeito do decreto de 6 de novembro de 1866 que concedeu gratuitamente liberdade aos escravos da nação que pudessem servir ao
Exército, e estendeu o mesmo benefício sendo eles casados às suas mulheres, foi um desses efeitos que se não podem limitar ao pequeno círculo onde diretamente se exercem. Além disso, nas condições difíceis em que o Brasil se achava então, quando a onda dos voluntários espontâneos estava sendo a custo suprida pelo recrutamento, odioso à população, porque era sorrateiro, vexatório, político, e sujeito a empenhos, é certo que o governo pensou em armar, resgatando-os, grande número de escravos. ${ }^{2}$ Os títulos de nobreza concedidos aos senhores que forneciam escravos para o Exército mostram o interesse que tinha o Estado em achar soldados entre os escravos.

Essa cooperação dos escravos com o Exército era o enobrecimento legal e social daquela classe. Nenhum povo, a menos que haja perdido o sentimento da própria dignidade, pode intencionalmente rebaixar os que estão encarregados de defendê-lo, os que fazem profissão de manter a integridade, a independência e a honra nacional. Por isso não era o Exército que o governo humilhava indo buscar soldados nas fileiras ínfimas dos escravos; eram os escravos todos que ele elevava. Entre o senhor que ele fazia titular, e o escravo que fazia soldado, a maior honra era para este. A significação de tais fatos não podia ser outra para a massa dos escravos brasileiros senão que o Estado, por sua própria dignidade, procuraria no futuro fazer cidadãos os companheiros daqueles que tinham ido morrer pela pátria no mesmo dia em que tiveram uma. A influência, na imaginação dessa classe, de semelhantes atos dos poderes públicos, aos quais ela atribui, na sua ignorância supersticiosa, mais coerência, memória, respeito próprio e sentimento de justiça de que eles com efeito têm, devia ter sido

\footnotetext{
${ }^{2}$ Sobre a questão se o governo devia forrar escravos de particulares para servirem no Paraguai como soldados, foi este no Conselho de Estado em novembro de 1866 o parecer do senador Nabuco: "Este meio seria odioso se os escravos fossem tais depois de soldados, se eles continuassem escravos como os oito mil escravos que Roma depois da batalha de Canas comprou e armou. Mas não é assim, os escravos comprados são libertos e por consequência cidadãos antes de serem soldados; são cidadãos-soldados. É a Constituição do Império que faz o liberto cidadão, e se não há desonra em que ele concorde com o seu voto para constituir os poderes políticos, porque haverá em ser ele soldado, em defender a pátria que o libertou e à qual ele pertence? Assim ao mesmo tempo e pelo mesmo ato se faz um grande serviço à emancipação, que é a causa da humanidade e outro grande serviço à guerra, que é a causa nacional... Se empregamos os escravos na causa da nossa Independência, por que não os empregaremos nesta guerra?".
} 
muito grande. Desde esse dia pelo menos o governo deu aos escravos uma classe social por aliada: o Exército.

A Fala do Trono de 22 de maio de 1867 foi para a emancipação como um raio, caindo de um céu sem nuvens. ${ }^{4}$ Esse oráculo sibilino em que o engenhoso eufemismo elemento servil amortecia o efeito da referência do chefe de Estado à escravidão e aos escravos - a instituição podia existir no país, mas o nome não devia ser pronunciado do alto do trono em pleno Parlamento - foi como a explosão de uma cratera. Aquele documento prendese intimamente a dois outros que representam importante papel em nossa história: a mensagem da junta de emancipação em França ao imperador e a resposta do ministro da Justiça em nome deste e do governo brasileiro. A segunda dessas peças humanitárias foi assinada pelo conselheiro Martim Francisco e a primeira pelos seguintes abolicionistas franceses: o duque de Broglie, Guizot, A. Cochin, Andaluz, Borsier, príncipe de Broglie, Gaumont, Léon Lavedan, Henri Martin, conde de Montalemberg, Henri Moreaum Edouard de Pressensém Wallon, Eugène Yung.

Nessa mensagem diziam esses homens, a maior parte deles conhecido do mundo inteiro: "Vossa Majestade é poderoso no seu Império; uma vontade de Vossa Majestade pode produzir a liberdade de dois milhões de homens". Não era assim a emancipação das gerações futuras que eles reclamavam em nome da humanidade e da justiça; era a emancipação dos próprios escravos existentes, esses e não outros. Na resposta do ministro não há uma só reserva quanto ao modo de entender a abolição da escravatura; o imperador agradece o alto apreço em que é tido por homens tão notáveis, e não insinua a mínima divergência de vistas com eles. A resposta deve ser explicada de acordo coma pergunta; o que se promete

\footnotetext{
3 "As medidas a que o governo recorreu ultimamente, impelido pelas necessidades da guerra, libertando escravos da nação e da Coroa, e premiando os cidadãos que ofereciam libertos para o exército, não só deve ter estimulado os espíritos mais sôfregos por essa reforma, como também derramado essa esperança entre os escravos. Todos nós podemos dar testemunho de que estes efeitos se vão sentindo". Palavras do conselheiro Paranhos no Conselho de Estado, Sessão de 2

de abril de 1867. - Trabalhos sobre a extinção da escravatura no Brasil, p. 50.
4 "O elemento servil no Império não pode deixar de merecer oportunamente a vossa consideração, provendo-se de modo que, respeitada a propriedade atual, e sem abalo profundo em nossa primeira indústria - a agricultura - sejam atendidos os altos interesses que se ligam à emancipação.”
}

com o que foi pedido. É só assim que as palavras finais do ministro da Justiça terão o seu verdadeiro relevo:

A emancipação dos escravos, consequência necessária da abolição do tráfico, é somente uma questão de forma e oportunidade. Quando as penosas circunstâncias em que se acha o país o consentirem, o governo brasileiro considerará como objeto de primeira importância a realização do que o espírito do cristianismo desde há muito reclama do mundo civilizado.

Aí está um compromisso claro e terminante, tomado solenemente perante a Europa em 1867 a favor de dois milhões de homens, os quais estão ainda - os que existem dentre eles - esperando que o Estado descubra a forma e encontre a oportunidade de realizar o que o espírito do cristianismo desde há muito reclama do mundo civilizado, e que este já realizou com exceção apenas do Brasil.

A iniciativa tomada contra a escravidão no Paraguai pelo conde d'Eu, marido da princesa imperial, como general em chefe do nosso Exército, foi outro compromisso aceito à face do mundo. Como poderia este acreditar que $\mathrm{o}$ ato do general brasileiro exigindo do vencido a abolição da escravatura, não envolvia para o vencedor a obrigação moral de fazer outro tanto no seu próprio território? Esse exército, cuja coragem e perseverança habilitou o príncipe que o comandava a impor ao inimigo o seu desejo humanitário, como uma ordem que foi logo obedecida, era composto em parte de homens que tinham passado pelo cativeiro. Talvez o conde d'Eu não tenha se lembrado disso ao reclamar a emancipação dos escravos na República, nem que os havia em número incomparavelmente maior no Império; mas o mundo não podia esquecer um e outro fato, ao ter conhecimento daquela nobre exigência e do modo como foi satisfeita.

"Se vós lhe concederdes [aos escravos] a liberdade que eles pedem", escrevia o príncipe ao governo provisório do Paraguai em Assunção, "tereis rompido solenemente com uma instituição que foi infelizmente legada a muitos povos da livre América por séculos de despotismo e de deplorável ignorância". A resposta a esse apelo foi um decreto em 2 de outubro de 1869, cujo artigo $1^{\circ}$ dizia: "Fica desde hoje abolida totalmente a escravidão no território da República". O compromisso nacional de fazer tudo o que estivesse ao alcance

${ }^{5}$ Vide íntegra dos dois documentos. O Abolicionista, Rio de Janeiro, 1880, número de novembro. 43 
do Império para imitar o procedimento do Paraguai foi tão claramente tomado por aquele episódio final da campanha, como se houvesse sido exarado no próprio Tratado de Paz. Essa dívida de honra só pode ser negada, admitindo-se o princípio de que é legítimo e honesto para uma nação derribar no território inimigo, por ela ocupado e à sua completa mercê, com o pretexto de humanidade do cristianismo, uma instituição da qual está firmemente resolvida a tirar dentro das suas fronteiras todo o lucro possível até a extinção das últimas vítimas. Semelhante noção, porém, reduziria a guerra à pirataria, o comandante de um exército a um chefe de salteadores, e é de todo inaceitável para os que julgam, na frase de John Brigth, "a lei moral tão obrigatória para as nações como o é para os indivíduos".

Quanto à esperança proveniente da agitação antes e depois da campanha parlamentar que deu em resultado a lei de 1871, e às promessas depois de feitas, baste-nos dizer em geral, por ora, que a oposição levantada contra aquele ato devia ter espelhado entre os escravos a crença de que o fim do seu cativeiro estava próximo. Os acessos de furor de muitos proprietários; a linguagem de descrédito usada contra a monarquia nas fazendas, cujas paredes também têm ouvidos; a representação do imperador, cujo nome é para os escravos sinônimo de força social e até de providência, como sendo o protetor de sua causa; e por fim o naufrágio total da campanha contra o governo; cada uma das diferentes emoções daquela época agitada parecia calculada para infundir no barro do escravo o espírito do homem e insuflar-lhe a liberdade.

Desde o dia em que a Fala do trono do gabinete Zacarias inesperadamente, sem que nada o anunciasse, suscitou a formidável questão do elemento servil, até o dia em que passou no Senado, no meio de aclamações populares e ficando o recinto coberto de flores, a lei Rio Branco, houve um período de ansiedade, incômoda para a lavoura; e para os escravos, pela razão contrária, cheia de esperança. A subida do visconde de Itaboraí em 1868, depois dos compromissos tomados naquela Fala e na célebre carta aos abolicionistas europeus, significava: ou que o imperador ligava então, por causa da guerra, maior importância ao estado do Tesouro que é a reforma servil, ou que em política, na experiência de Dom Pedro II, a linha reta não era o caminho mais curto de um ponto a outro. Como se sabe também, aquele ministro caiu sobretudo pela atitude assumida nesta mesma questão pelos seus adversários, e pelos amigos que o queriam ver por terra. A chamada do visconde de São Vicente para substituí-lo foi sinal que a reforma da emancipação, que ficará para sempre associada entre outros com o nome daquele estadista, ia de fato ser tentada; infelizmente o presidente do Conselho organizou um ministério dividido entre si, e que por isso teve que ceder o seu lugar a uma combinação mais homogênea para o fim que a nação e a Coroa tinham em vista. Foi esse o ministério Rio Branco.

Durante todo esse tempo de retrocesso e hesitação, o Partido Liberal, que inscrevera no seu programa em 1869 "a emancipação dos escravos", agitou por todos os modos o país, no Senado, na imprensa, em conferências públicas. "Adiar indefinidamente a questão", dizia no Senado aos conservadores naquele ano o senador Nabuco, presidente do Centro liberal, "não é possível; nisto não consente o Partido Liberal, que desenganado de que nada fareis há de agitar a questão". E em 1870, com mais força, insistia aquele estadista:

Senhores, este negócio é muito grave; é a questão mais importante da sociedade brasileira, e é imprudência abandoná-la ao azar. Quereis saber as consequências? Hei de dizê-lo com toda a sinceridade, com toda a força das minhas convicções: o pouco serve hoje, e o mundo amanhã não basta. As coisas políticas têm por principal condição a oportunidade. As reformas por poucas que sejam valem muito na ocasião, não satisfazem depois, ainda que sejam amplas. Não quereis os meios graduais; pois bem, haveis de ter os meios simultâneos; não quereis as consequências de uma medida regulada por vós, pausadamente, haveis de ter a incerteza da imprevidência; não quereis ter os inconvenientes econômicos por que passaram as Antilhas inglesas e francesas, correis o risco de ter os horrores de São Domingos.

Como podia a agitação de um dos grandes partidos nacionais, havia pouco ainda no poder, em favor dos escravos, deixar de inspirar-lhes a confiança de que a sua liberdade, talvez próxima, talvez distante, era em todo caso certa? O grito de combate que repercutia no país não era "a emancipação dos nascituros", nem há senão figuradamente emancipação de indivíduos não existentes; mas sim "a emancipação dos escravos". Os direitos alegados, os argumentos produzidos, eram todos aplicáveis às gerações atuais. Semelhante terremoto não podia restringir o seu tremendo abalo à área marcada, desmoronava o solo não edificado sem fender a parte contígua. $\mathrm{O}$ impulso não era dado aos interesses de partido, mas à consciência humana, e quando 
de uma revolução se quer fazer uma reforma, é preciso pelo menos que esta tenha o leito bastante largo para deixar passar a torrente. Tudo o que se disse durante o período da incerteza, quando a oposição tratava de arrancar ao Partido Conservador a reforma que este lhe sonegava ${ }^{6}$ constitui outras tantas promessas feitas solenemente aos escravos. Na agitação não se teve o cuidado de dizer a estes que a medida não era a seu favor, mas somente em favor de seus filhos; pelo contrário, falava-se das gerações atuais e das gerações futuras conjuntamente, e na bandeira levantada do Norte ao Sul não havia artigos de leis inscritos, havia apenas o sinal do combate em uma palavra, emancipação.

Agora vejamos as promessas que se podiam legitimamente deduzir dessa mesma lei de 28 de setembro de 1871, que foi, e não podia deixar de ser, uma tremenda decepção para os escravos, os quais ouviam antes dizer que o imperador queria a emancipação e que a emancipação ia ser feita. Considerado a princípio como uma espoliação pela aristocracia territorial, aquele ato legislativo que não lhe restringiu de modo algum os direitos adquiridos, tornou-se com o tempo o seu melhor baluarte. Mas não é o que se diz hoje, que tem valor para nós; é o que se dizia antes da lei. Para medir-lhe o alcance é preciso atendermos ao que pensavam então, não os que a fizeram, mas os que a combateram. Nesse caso, a previdência, curioso resultado, da cegueira moral, esteve do lado destes; foram eles que mediram verdadeiramente as consequências reais da lei, que lhe apontaram as incoerências e os absurdos, e que vaticinaram que essa não podia ser, e não havia de ser, a solução de tão grande problema.

\footnotetext{
${ }^{6}$ Deu-se em 1870 um fato muito curioso. A comissão especial de que era relator o Sr. Teixeira Júnior requereu, e a Câmara votou que se solicitasse com urgência do governo cópia dos projetos submetidos ao Conselho de Estado em 1867 e 1868 e dos pareceres dos membros do Conselho: a esse pedido responderam os ministros da Justiça. (J.O. Nebias) e do Império (Paulino de Souza) que não havia papéis alguns nas suas respectivas secretarias. No parecer disse a comissão: "Sob caráter confidencial e com recomendação reiterada da maior reserva foi mostrada à comissão por um dos dignos membros do gabinete uma cópia de quatro atas das sessões do Conselho de Estado e do último projeto ali examinado. Nestas condições, pois, a comissão não pode revelar nenhuma das opiniões exaradas nesses documentos." Art. $7^{\circ}$ da lei de 15 de outubro de 1827: "Os conselheiros de estado são responsáveis pelos conselhos que derem, etc.” Os grifos são do parecer.
} 